\title{
Quantifying the Differences in Documentation and Modeling Levels for Building Pathology and Diagnostics
}

\author{
Rebecca Napolitano $^{1}$ (1) $\cdot$ Michael Hess $^{2} \cdot$ Branko Glisic $^{1}$
}

Received: 5 February 2019 / Accepted: 28 June 2019 / Published online: 3 July 2019

(c) The Author(s) 2019

\begin{abstract}
Building pathology and diagnostics enable a practitioner to quantify the severity of damage to an existing structure as well as prioritize interventive and preventive measures. Two key aspects of building pathology and diagnostics are documentation and analysis to understand how damage could have occurred on a structure and how it affects overall stability. Within these two methods there are various levels which a practitioner can utilize. The aim of the present work is to quantify the differences in documentation and modeling levels to understand how they affect the overall process of building pathology and delineate the advantages and disadvantages of each approach. Using combinations of photogrammetry, laser scanning, thermal imaging, distinct element modeling, and finite-distinct element modeling, this work seeks to understand how differences in the level of numerical modeling affect damage diagnoses as well as how differences in documentation levels affect damage diagnoses. In particular, the advantages and disadvantages of simulations using simplified micro-modeling versus detailed micro-modeling, the effects of small perturbations to modeling geometry, and the influences of initial conditions are explored. These questions are examined through the use of two case studies including the foundation walls of the Baptistery di San Giovanni in Florence, Italy and a wall in Palazzo Vecchio in Florence, Italy.
\end{abstract}

\section{Introduction}

Building pathology and diagnostics focuses on the degradation and downfall of existing structures. By assessing the condition of a building, the sources of defects and paths for intervention can be presented in an actionable and intelligible manner [28]. In particular, the severity of defects can be quantified, the sources can be identified, and plans for intervention and prevention can be prioritized [79]. The condition of an existing structure can be assessed by assembling relevant data regarding a building, documenting it with reality-based imaging methods, and using computational modeling to simulate its response to a spectrum of loading conditions. During this process both the documentation and computational modeling can be carried out at different levels depending on the scope and budget of a project. The overall aim of this paper is to understand how the different levels of

Rebecca Napolitano

rkn2@princeton.edu

1 Department of Civil and Environmental Engineering, Princeton University, Princeton, USA

2 Department of Civil Engineering, University of California San Diego, San Diego, USA documentation and computational modeling can affect the process of building pathology and what are the advantages and disadvantages of the different approaches.

Letellier [39] and Santana and Patias [54] outline three main levels of documentation (Fig. 1): (1) reconnaissance, (2) preliminary, and (3) detailed. Reconnaissance documentation, documentation level 1 (DL1) uses a photographic report, an initial condition assessment, and descriptive sketches to create a not-to-scale representation of a site. This level of documentation cannot be used to quantitatively or qualitatively understand how damage occurred on a structure since there is no geometry measured. The use of reconaissance documentation for cultural heritage is common and often occurs in the form of spherical panoramas [1, 23, 46, 80].

Preliminary documentation (DL2) uses measured drawings, digital photography, and GPS mapping to create a record which has plan and elevation drawings with an accuracy of $\pm 10 \mathrm{~cm}$ and detailed structural elements with an accuracy of $\pm 2 \mathrm{~cm}$. While this level of recording yields simple geometries which are conducive for computational modeling, there are an assortment of practical issues which must be addressed in the context of a project's scope. Santana and Patias (2009) outline that simplified geometries can 
Fig. 1 Illustration of the levels of documentation for heritage structures. The figure augments an existing figure from Napolitano et al. [52] which is originally based on previous literature $[39,54]$



often miss the fact that on an existing structure, nothing is straight, square, or horizontal [54]. Depending on the scope of a project or the level of computational modeling that is used for simulations, this can play a role in understanding existing damage on a structure. For examples of preliminary documentation on cultural heritage sites, see $[9,65]$.

Detailed documentation (DL3) uses measured drawings, digital photography, GPS mapping, photogrammetry, and laser scanning, to create a record which has plan and elevation drawings with an accuracy of $\pm 1 \mathrm{~cm}$ and detailed structural elements with an accuracy of $\pm 2 \mathrm{~mm}$. While this approach documents the geometry and any existing cracks on a building with high accuracy, it also has its drawbacks. As outlined in Napolitano et al. [52], this level of documentation can be costly for a project in terms of time, funding, and data management; therefore, this level of documentation should only be used when it is within the scope of a project. For examples of detailed documentation on cultural heritage sites, see [24, 33, 71, 76]

These levels of documentation detail, however, do not address subsurface documentation. The use of thermal imaging and ground penetrating radar (GPR) are becoming more prominent on projects examining existing damage conditions and structural stability $[12,14,21,34,36,43,62,75,78]$. To include this supplementary level of documentation, the addition of a fourth level is proposed in Fig. 1. Like approaches 1-3 the fourth, multi-level documentation, is cumulative. Multi-level documentation (DL4) uses measured drawings, digital photography, GPS mapping, photogrammetry, laser scanning, thermal imaging, and GPR. Similar to detailed documentation, plan and elevation drawings must have an accuracy of $\pm 1 \mathrm{~cm}$ and detailed structural elements must have an accuracy of $\pm 2 \mathrm{~mm}$

Documentation is not the only sector of building pathology which has levels a user must select from. Additionally, the computational modeling can be carried out on three main levels. Based on Lourenco [40] and Asteris et al. [4], the three main levels for modeling masonry are as follows: (1) macro-modeling, (2) simplified micro-modeling, (3) detailed micro-modeling (Fig. 2). In the first level of refinement (Fig. 2b), modeling level 1 (ML1), the constituents of a building are divided into continuum macro elements. While this method is applicable for understanding the global stability of a building, it is not able to capture large rotations or the complete detachment of blocks. This level of refinement was used by Milani et al. to examine

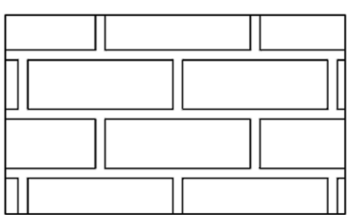

A

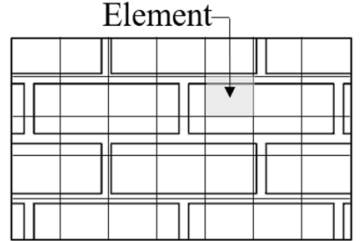

B

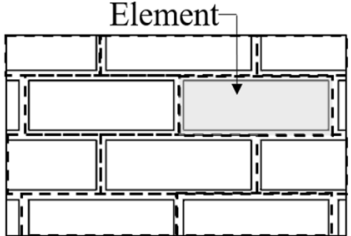

C



D

Fig. 2 Schematic illustrating different levels of modeling of the physical wall in $\mathbf{a}, \mathbf{b}$ macro-modeling, $\mathbf{c}$ simplified micro-modeling, $\mathbf{d}$ detailed micro-modeling. This figure is based on previous literature [4] 
how damage occurred on the narthex of the Church of the Nativity in Bethlehem [45]. Using non-linear finite element analysis, this work was able to understand how earthquake loading could have induced much of the damage that can still be seen today. Additional works have also utilized this level of modeling for cultural heritage projects $[8,18,41,55,59]$.

The second level of refinement (ML2, Fig. 2c), a middle ground of computation and accuracy, uses a zero-thickness interface between discrete blocks to model the joint interactions. The elements contain the geometry of the individual bricks fictitiously expanded to include the geometry of the joints; an interface is defined between these approximate elements. This approach was used in Sarhosis and Sheng (2014) to examine the formation of cracks on experimental masonry walls [69]. This work sought to understand the effects of material parameters using distinct element modeling (DEM). Many previous works have also found this level of refinement to be successful for studying historic structures $[10$, $11,37,44,58]$.

The third level of refinement (ML3, Fig. 2d) models the mortar joints as separate elements with their true thickness; interfaces are defined between the mortar and the masonry units. While this method can lead to increased accuracy, the computational cost can be high (this will be discussed later in this paper). An understanding of a project's needs and constraints should dictate the applicable level of refinement. Specifically this level of refinement was used to understand the causes of cracking on the two case studies examined in this paper: a foundation wall of the Baptistery di San Giovanni in Florence, Italy and a wall in Palazzo Vecchio. For successful applications of this level of refinement, see [47-49]

While simulation and documentation work have been done on all levels, there is not yet an understanding of how combinations of different levels affect the ensuing simulation results. By understanding how different levels of documentation and modeling change building pathology and diagnostics, this work will enable more efficient workflows for projects and garner more accurate assessment for interventions and preventitive conservation [74]. The aim of this work is to examine the influence of initial conditions such as the level of modeling, geometry, and material properties to understand the importance of multi-level and integrated documentation for building pathology. Therefore, this work will address the following research questions:

1. How do differences in numerical model refinement alter diagnoses? Specifically:

(a) What are the advantages/disadvantages of simulations using simplified micro-modeling versus detailed micro-modeling in terms of both computational power and ensuing results?
2. How do differences in documentation levels alter diagnoses? Specifically:

(a) How do perturbations in detailed micro-modeling affect the results of simulation (ie how accurate does documentation of a structure need to be)?

(b) How can initial assumptions about the existence of damage or material properties alter the results of simulation?

To understand the implications of multi-level and integrated documentation, this work (1) compares the results of simulations for a masonry wall modeled with both simplified and detailed micro-modeling, (2) compares two masonry walls modeled with perturbations in macro-scale geometry, (3) model two masonry walls with different initial conditions to understand how that affects diagnosis of damage. The analyses are carried out using combinations of DL2, DL3, D14, ML2, and ML3.

\section{Case Studies}

Case studies of two masonry walls were used to address the questions presented in Sect. 1.

\subsection{Foundation Wall of the Baptistery di San Giovanni}

The Baptistery di San Giovanni, a quasi-symmetrical octagonal structure, is located in the heart of Florence, Italy. It is comprised of eight curved ceiling panels which make up the dome of the building; the dome itself is made of two shells which are tied together with periodic masonry ribs. The earliest historical reference to the Baptistery occurs in $897 \mathrm{AD}$; however, the foundation of the building is much older. The ecclesiastical edifice rests upon the remains of earlier structures, whose use and intention have been the cause for much debate over the centuries. Excavations in the early 20th century revealed that its walls rest upon Roman constructions that date to the 3rd century AD [29]. Presently, the foundation walls are riddled with cracks for which the causes are unknown. This case study was used to examine how the effects of simplified micro-modeling versus detailed micro-modeling, alterations in micro-scale modeling, and uncertainty in initial conditions can affect building pathology and diagnostics.

\subsection{The Room of the Elements in Palazzo Vecchio}

Palazzo Vecchio, currently the city hall in Florence, Italy, has been gradually built up over the course of many eras. Medieval buildings, which were aggregated over time, 
surround a 13th-century front facade. The second case study examined in this paper considers a room within the Southeast corner of the Palazzo, Sala degli Elementi (or The Room of the Elements). As early as 1558 there were concerns with the integrity of the Southeast corner of Palazzo Vecchio, as was indicated by an invoice directed to Giorgio Vasari for steel reinforcing bars-later detected using metal detection equipment [2]. Damage associated with the building's complex construction has therefore been a topic of concern since the times when the connections were being made. Presently, cracking is occurring in the stone wall and permeating through the fresco layer. This case study was used to examine how the effects of alterations in micro-scale modeling and uncertainty in material properties can affect building pathology and diagnostics.

\section{Methodology}

\subsection{Documentation of Geometry and Current Conditions}

\subsubsection{Foundation Wall of the Baptistery di San Giovanni}

As the Baptistery has evolved over many centuries, there are a variety of connections, materials, and techniques used in its construction. To holistically understand this structure, archival research was initially completed. Subsequent to archival research a detailed terrestrial laser scanning (TLS) campaign was outlined. Laser scanning is a technique which has been widely used in cultural heritage $[20,38,73]$ and structural health monitoring $[25,26,53]$. In the Baptistery di San Giovanni, a Faro Focus 3D $\times 130$ laser scanner with 1-2 $\mathrm{mm}$ resolution was used; 14 scans were taken in the region surrounding the cracked foundation wall and aligned using Faro Scene. Automatic cloud-to-cloud alignment was used to minimize any issues arising from manual registration. The model generated using TLS can be seen in Fig. 3a. In addition to capturing the geometry of the foundation wall with a laser scanner, a Canon 5D DSLR camera was also used for photographs of the existing conditions.

An orthographic projection of the 3D model was imported into AutoCAD, the locations of the stones and mortar were traced manually, and a 3D model of the foundation wall was extruded. The geometry of the stones through the depth of the wall is modeled consistently since it was possible to examine the interior in broken sections of the wall. In addition to generating a detailed micro-model of the foundation wall, a macro-model of the entire structure was also generated from additional laser scan data. This macro-scale model was used to calculate the boundary conditions on the foundation wall and will be discussed below.

A map of the existing cracks on the foundation wall can be found in Fig. 3b. On this diagram, red indicates cracking over $1 \mathrm{~cm}$, yellow indicates cracking on the order of $1 \mathrm{~mm}$, and orange indicates cracking in between these two limits. Figure $3 \mathrm{~b}$ illustrates that most of the cracking is present in the center of the foundation wall. Here there are two sections where the cracks persist through the height of the wall and are on the order of $1 \mathrm{~cm}$ or greater. Smaller cracks radiate out from these larger ones. Additionally, there is a large crack in the top right of the wall.
Fig. 3 a 3D model generated using TLS, b existing cracks on the foundation wall. Red indicates cracking over $1 \mathrm{~cm}$; yellow indicates cracking on the order of $1 \mathrm{~mm}$; orange indicates cracking in between these two limits. Figure adapted from [50]. (Color figure online)
A

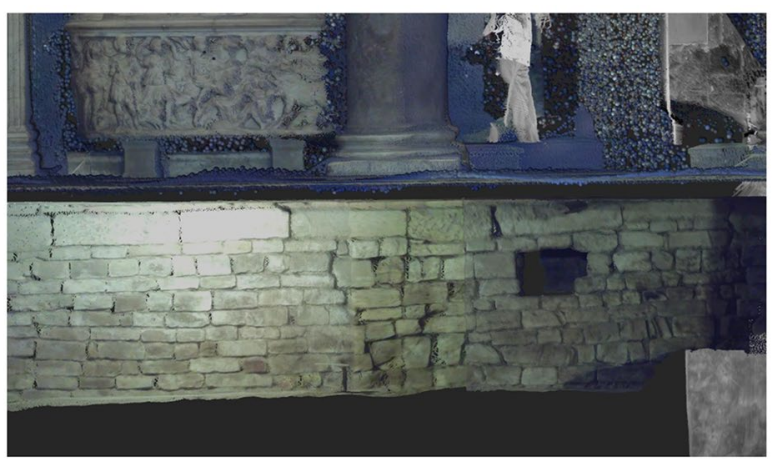

B

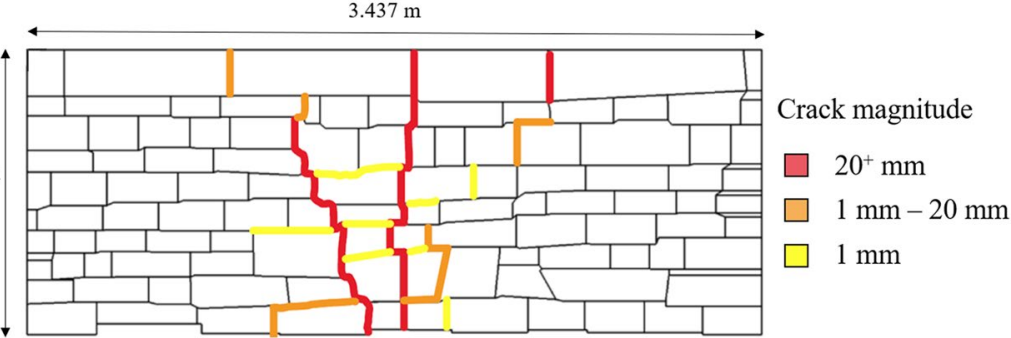




\subsubsection{The Room of the Elements in Palazzo Vecchio}

Similar to the foundation wall in the Baptistery di San Giovanni, a Faro Focus $3 \mathrm{D} \times 130 \mathrm{TLS}$ with $1-2 \mathrm{~mm}$ resolution was used to record the existing conditions of the walls. Additionally, terrestrial photogrammetry was used to supplement the TLS point cloud. 200 images were taken in the room using a Canon 5D DSLR camera. The point clouds generated using TLS and photogrammetry were combined and the raw images were used to texture the TLS model. Figure 4 shows the locations of some of the cracks visible on the surface of the fresco.

While detailed documentation was generated using lineof-sight methods, the extent of the damages as well as the geometry of masonry behind the fresco was not able to be captured. Thus, 72 thermal images were acquired using a FLIR A615 camera. The infrared resolution on the thermal camera was $640 \times 480$ pixels, the thermal sensitivity was $<0.05{ }^{\circ} \mathrm{C}$, and the accuracy was $\pm 2{ }^{\circ} \mathrm{C}$. Best practices for setup and acquisition were carried out according to the ASTM C1153-10 standard [30]. The thermal images mosaics were draped onto the 3D laser scan model to enable direct interaction between different layers of information within the model environment (Fig. 5).

Since the emissivity varies between stone and infill, the thermal mosaics could be used to derive the geometry of the wall in a non-destructive manner. Since the cracks are not immediately visible, only a qualitative map of the cracking for this wall was generated (Fig. 6). The red lines indicate relatively large cracks $(1 \mathrm{~cm}+)$, the orange indicates midlevel cracking $(1 \mathrm{~mm}-1 \mathrm{~cm})$, and the yellow cracks indicate minor cracking $(<1 \mathrm{~mm})$. Figure 6 illustrates that the regions with the highest degree of cracking occur in proximity to the doorways. Additionally, a few small areas of cracking can be seen in the top-middle section of the wall.

\subsection{Deriving Boundary Conditions From Global Models}

Previous literature has found that it is acceptable to examine select regions of a structure if the boundary conditions from the global model are incorporated into the analysis $[4,13,32,61]$. For both structures, linear FEM was carried out to calculate the boundary conditions specific to the wall sections. Smeared macro-models were used for the global analysis. In Fig. 3a, it can be seen that there are two predominant load paths into the foundations. On top of the foundation wall there is a column which contributes in a concentrated area and a solid masonry wall which contributes a distributed load. On Palazzo Vecchio, the loads from the upper part of the superstructure on the wall section were calculated and applied as a distributed load. In addition to
Fig. 4 Photographs illustrating cracks which are permeating the fresco layer. a Shows the full wall and the locations of specific cracks, b-f show close ups of specific cracks. Figure adapted from [49]
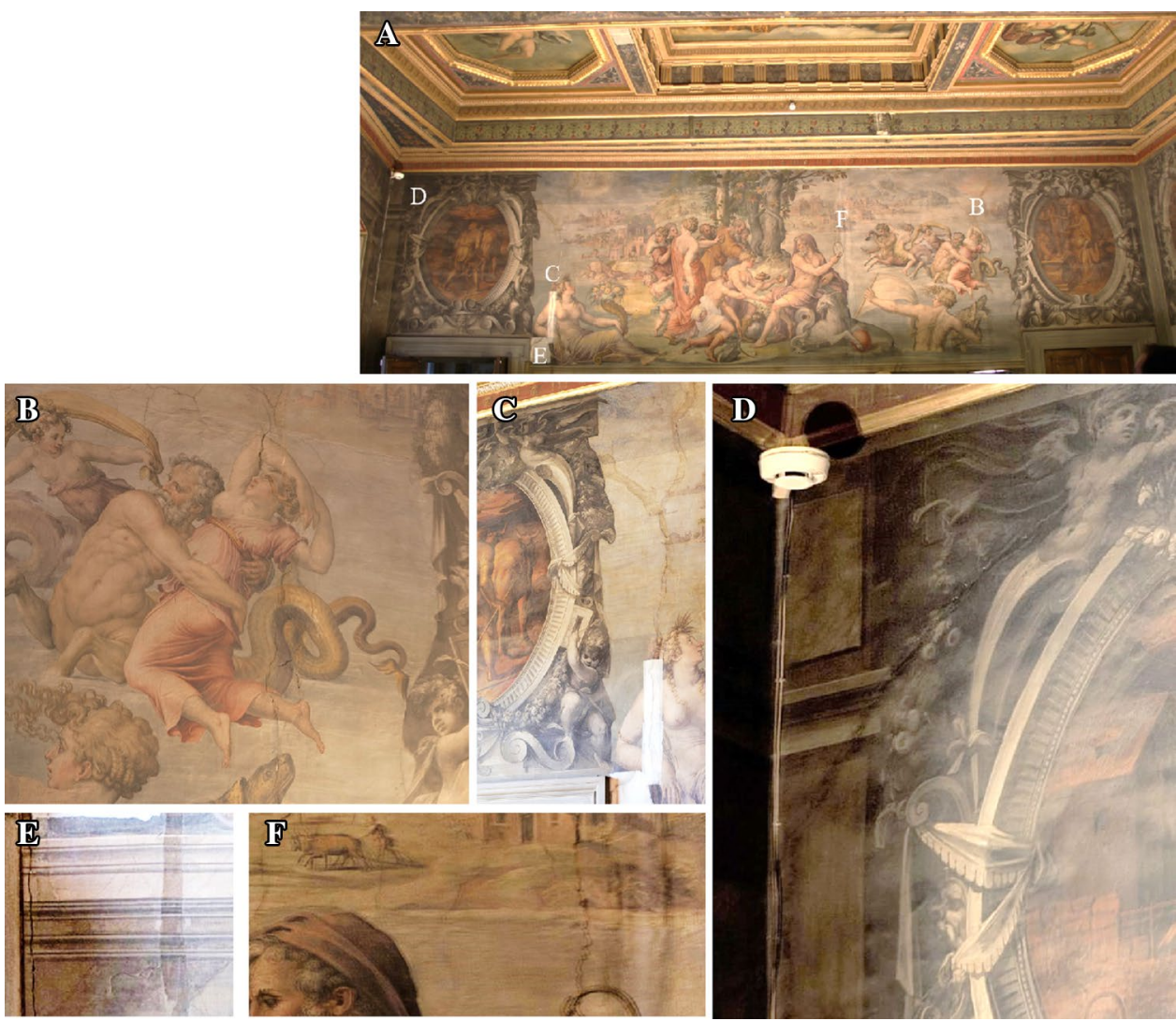
Fig. 5 Example of thermal image mosaic draped onto 3D laser scan model in the Room of the Elements
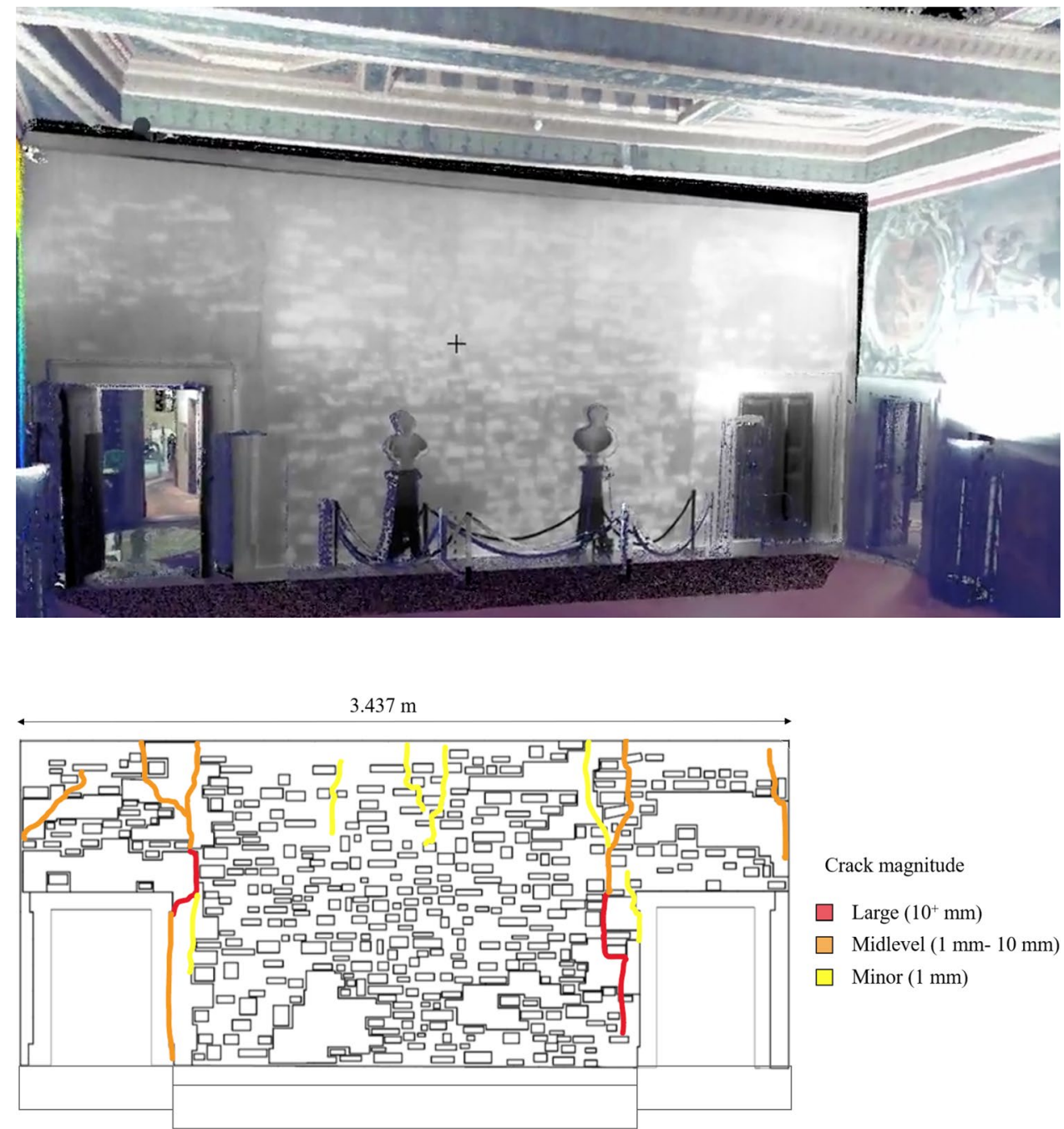

Fig. 6 Existing cracks on the wall in the Room of the Elements. Figure adapted from [49] in finite-distinct element modeling (FDEM) meaning that the geometry of individual stones can vary based on the applied loading [15]. FDEM has also been applied widely to masonry construction $[6,7,48,51,66,72]$. DEM was used to simulate the simplified micro-model(stones were individually modeled) and FDEM was used to simulate the detailed micro-model (stones were individually modeled and the mortar was explicitly modeled).

\subsubsection{Effects of Simplified Micro-modeling Versus Detailed Micro-modeling}

To understand the effects of simplified micro-modeling versus detailed micro-modeling, two configurations of the foundation wall of the Baptistery di San Giovanni were generated. Figure 7 a shows the foundation wall modeled as a simplified micro-model: the mortar joints are expanded into the geometry of the stones. For each side of the stone that is in contact with the mortar, the stone is fictitiously expanded for half the width of the mortar joint. 

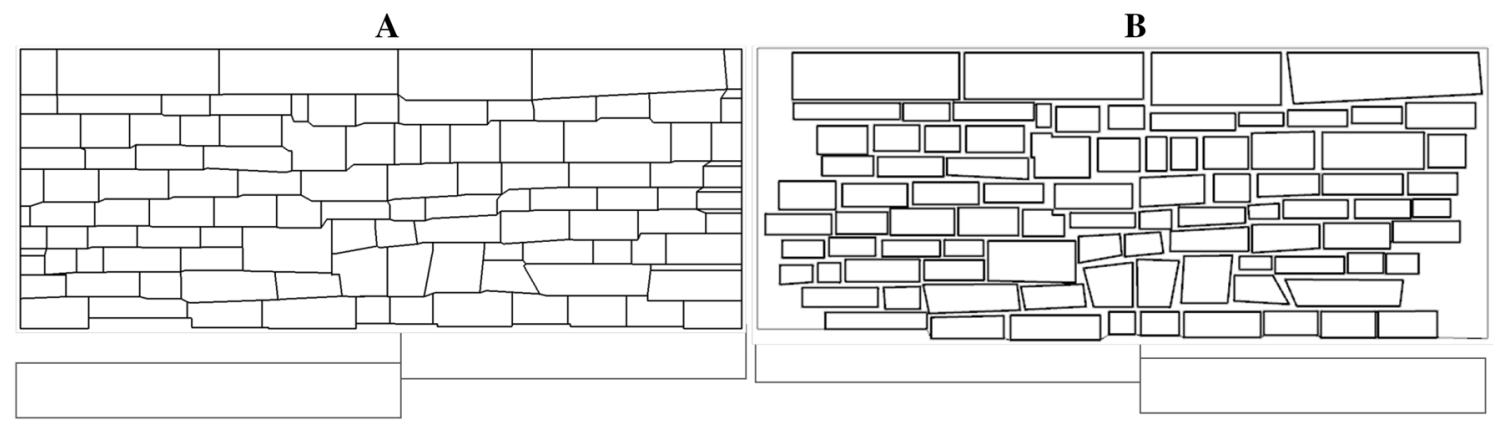

Fig. 7 Different levels of modeling for the foundation wall; a simplified-micro-model, b detailed-micro-model

Table 1 Material properties of blocks in the masonry wall

\begin{tabular}{lll}
\hline Property & Stone & Mortar \\
\hline Density, $\rho\left(\mathrm{kg} / \mathrm{m}^{3}\right)$ & $2300[5]$ & $1540[77]$ \\
Young's modulus, $E(\mathrm{GPa})$ & $52[5]$ & $0.5[67]$ \\
\hline
\end{tabular}

The interface between the two fictitiously expanded stones is deduced from the stiffness of the real joints. Figure $7 \mathrm{~b}$ depicts the foundation wall modeled using detailed micromodeling: the joints are modeled explicitly as a finite element mesh and the stones are modeled as individual finite element meshes.

The computational modeling of the walls is done in 3DEC — a software package for distinct element modeling and finite-distinct element modeling. The geometric representation of the walls in Fig. 7 is based on non-uniform blocks of polyhedral form. For the distinct element model in Fig. 7b, the stones were assumed to behave as rigid bodies. For the finite-distinct element model in Fig. 7a, the stones were assumed to behave deformably.

A Mohr-Coulomb constitutive model was used to describe the behavior of the interfaces [57]. For the distinct element model, only the density of the stone, $\rho_{\text {stone }}$, the normal stiffness of the joints, $j_{n s}$, the shear stiffness of the joints, $j_{s s}$, the friction angle, $\phi$, the cohesion, $c$, and the tensile strength of the joints, $j_{t e n}$, were required since a rigid block model was used. For the finite-distinct element model the density of the mortar, $\rho_{\text {mortar }}$, Young's modulus of the mortar, $E_{\text {mortar }}$, and Young's modulus of the stone, $E_{\text {stone }}$, were additionally required. The material properties for the mortar and the stones used in the distinct element model and the finite-distinct element model can be found in Tables 1 and 2 respectively. Previous works have used values from the literature when experimental testing is not possible and have had success $[16,17,49,68]$. Additionally, without destructive testing an approximation was made where the joint materials have been assumed to be the same for the different interactions.
Table 2 Material properties of joints in the masonry wall

\begin{tabular}{ll}
\hline Property & Value \\
\hline Joint normal stiffness, $j_{n s}(\mathrm{~Pa} / \mathrm{m})$ & $50 \times 10^{9}[67]$ \\
Joint shear stiffness, $j_{s s}(\mathrm{~Pa} / \mathrm{m})$ & $30 \times 10^{9}[67]$ \\
Friction angle, $\phi($ degree $)$ & $30[67]$ \\
Joint cohesion, $c(\mathrm{~Pa})$ & $1[60]$ \\
Joint tensile strength, $j_{\text {ten }}(\mathrm{MPa})$ & $0.92[19]$ \\
\hline
\end{tabular}

Both cases were subjected to three different loading schemes to understand the difference in the two modeling approaches:

- dead load only

- dead load $+0.5 \mathrm{~m}$ of settlement on the left side as shown in Fig. $7 \mathrm{a}$

- dead load $+0.5 \mathrm{~m}$ of settlement on the right side as shown in Fig. 7b

\subsubsection{Alterations in Geometry During Detailed-Micro-modeling}

Aside from modeling the foundation wall with its current geometry of stones, the wall was also modeled two other ways: (1) small perturbations were made to a region of interest susceptible to cracking and (2) the geometry of the wall was idealized to an isodomic pattern of masonry. All three configurations of the stones can be seen in Fig. 8.

The dashed boxes in Fig. 8 outline the region where a large crack can currently be seen in the foundation wall. In the configuration where the geometry reflects the true structure (Fig. 8a), there is a clear divide between geometry on the left and right sides of the wall. Figure $8 \mathrm{~b}$ is a variation where the blocks outside of the susceptible region have not been altered. However, the blocks that comprise the region of interest have been perturbed to increase the path length of the joint in the middle. Figure $8 \mathrm{c}$ is a variation where the blocks are placed ideally, maximizing the length of the path a crack would have to travel. All three configurations of the 




A

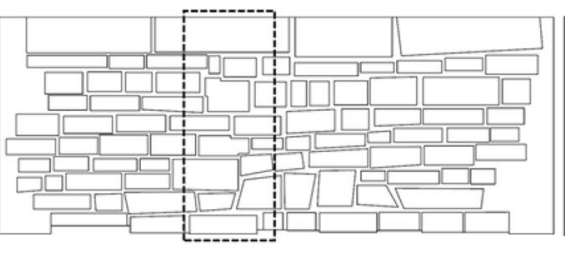

B

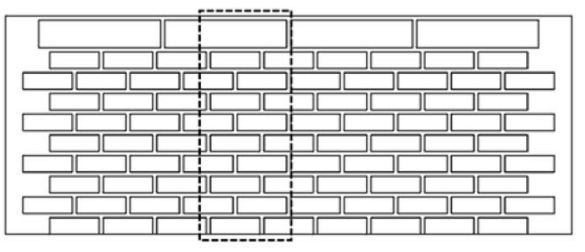

C

Fig. 8 a True locations of stones, $\mathbf{b}$ perturbation of the locations of stones within the susceptible region, $\mathbf{c}$ idealized, isodomic pattern

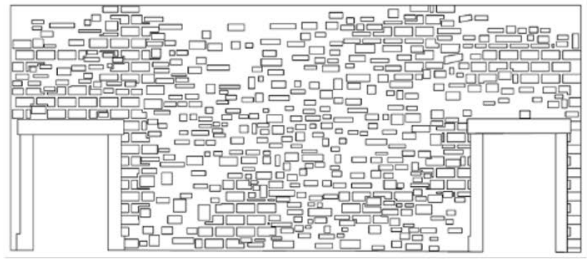

A

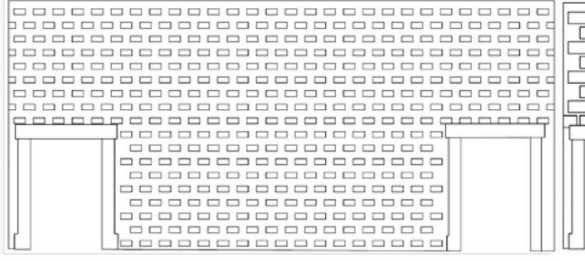

B

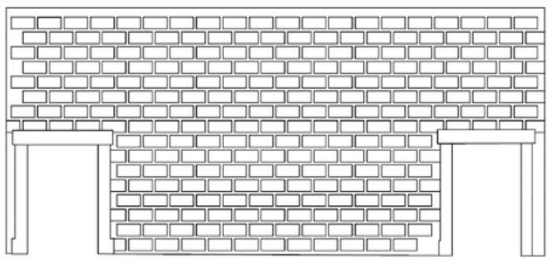

C

Fig. 9 Detailed-micro-model of a wall of the Room of the Elements: a real locations of stones, $\mathbf{b}$ semi-idealized pattern of stones, $\mathbf{c}$ idealized pattern of stones

Table 3 Material properties for finite-distinct element model of the Room of the Elements

\begin{tabular}{lllll}
\hline Property & Stone & Mortar & Brick & Infill \\
\hline $\begin{array}{l}\text { Density, } \rho\left(\mathrm{kg} / \mathrm{m}^{3}\right) \\
\begin{array}{l}\text { Young's modulus, } E \\
(\mathrm{GPa})\end{array}\end{array}$ & $2713[5]$ & $1540[77]$ & $2000[51]$ & $1800[48]$ \\
& & $0.5[67]$ & $6[67]$ & $3.37[27]$ \\
\end{tabular}

wall were subjected to $0.05 \mathrm{~m}$ of settlement on the left side to examine the differences in how each wall behaved under the same loading conditions. Settlement of $0.05 \mathrm{~m}$ on the left side was simulated because in a previous work it was found to be the most probable cause of the existing damage from a series of other loading combinations $[47,50]$. The material properties for the mortar and the stones can be found in Tables 1 and 2.

In addition to examining the Baptistery of Florence, the Room of the Elements at Palazzo Vecchio in Florence is also examined in a similar manner. The existing configuration was captured using the ground truth geometry of the terrestrial laser scan model and the thermal image mosaics [29]. Aside from modeling the wall with its current geometry of stones, the wall was also modeled two other ways: (1) semiideal and (2) ideal. The semi-idealized model uses stone and mortar dimensions consistent with the exterior of Palazzo Vecchio, and the idealized model uses the same ratio of mortar and stone seen in the thermal image and organized into an isodomic pattern [29]. All three configurations of the stones can be seen in Fig. 9. The material properties can be found in Tables 2 and 3.

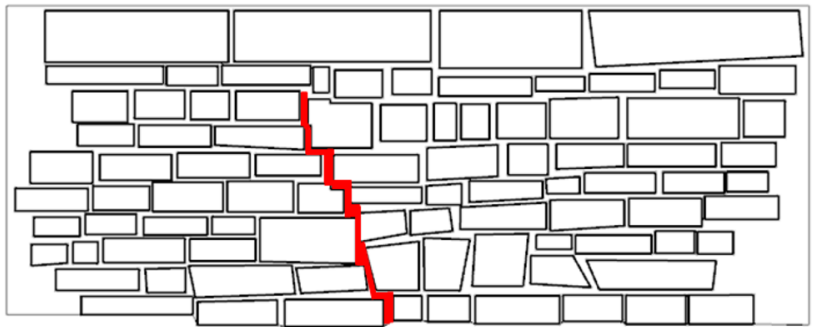

Fig. 10 Foundation wall with the joint in question highlighted in red. This wall was simulated to see how large the difference would be if this was modeled as $\mathrm{c}=0$ or $\mathrm{c} \neq 0$. (Color figure online)

\subsubsection{Effects of Initial Assumptions}

As outlined in [50], it was unknown if the crack highlighted in red in Fig. 10 on the foundation wall of the Baptistery had been present during the phase when the upper sections of the baptistery were being constructed or if it was a large crack that had developed since then. The theory that it was it was present prior to the construction of the upper parts of the building was driven by the fact that the stones in this region lined up in almost a continuous path throughout the height of the wall. This initial condition, termed $c=0$, was simulated by decreasing $j_{n s}, j_{s s}$, and $\phi$ to values associated with dry-joint masonry [57]; additionally, $c$ and $j_{\text {ten }}$ were set to zero at this isolated region. While this case was preliminarily tested in [50], the concept of how the initial assumption changed the results of diagnosis was not and will be examined in the present work. 
Additionally, models with two different initial conditions for the walls of the Room of the Elements were simulated. For the Room of the Elements, there are no records or indications of the masonry configuration since the walls are completely covered in plaster. While the location of stones and mortar could be elucidated from the combination of the thermal imaging and the terrestrial laser scanning, there were sections where it was not clear if it was concrete infill ( $e=0.92)$ or intentionally laid brick $(e=0.81-0.94)$ since the emissivity ranges overlap [31].

Ground penetrating radar would have been able to show what the material in these regions was, however that was outside the scope and facilities of the current work. To understand how these regions of unknown material could affect the diagnosis of cracks, geometry for each configuration was generated. Figure 11a illustrates the wall with bricks in the unidentified regions and Fig. $11 \mathrm{~b}$ depicts the wall with concrete infill in the unidentified regions. While these cases were preliminarily discussed in [49], the concept of how the initial assumption changed the results of building pathology and diagnostics was not and will be examined in the present work. $0.1 \mathrm{~m}$ of settlement was induced in the middle section of the wall (Fig. 6) as in a previous study [49] it was found to be the most probable damage mechanism.

\section{Results and Discussion}

\subsection{Effects of Simplified Micro-modeling Versus Detailed Micro-modeling}

The effects of simplified micro-modeling versus detailed micro-modeling were compared for the foundation wall of the Baptistery di San Giovanni. Figure 12 compares the crack patterns and magnitudes formed under three different load cases for the two different levels of modeling: simplified and detailed. As can be seen in Fig. 12, the detailed micro-model consistently simulates the formation of wider

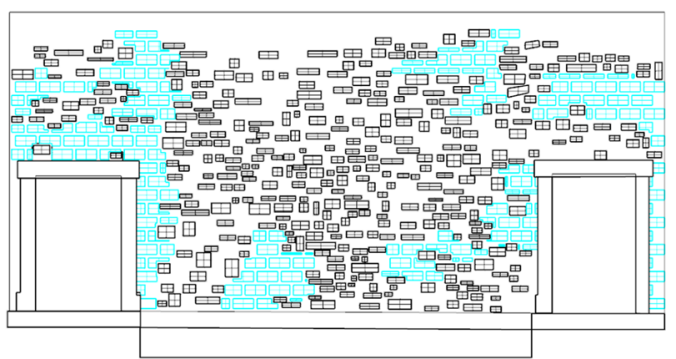

A

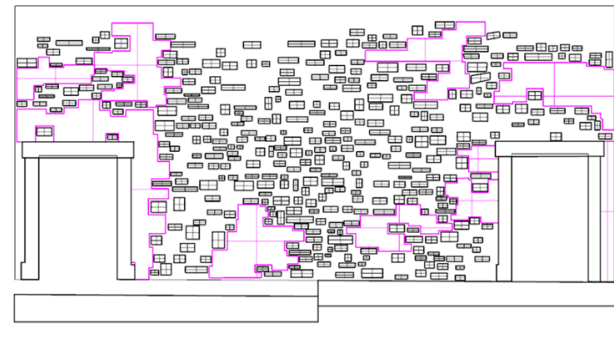

B

Fig. 11 Input geometry for simulation for the Room of the Elements: a with unidentified regions assumed to be brick, b with unidentified regions assumed to be concrete infill

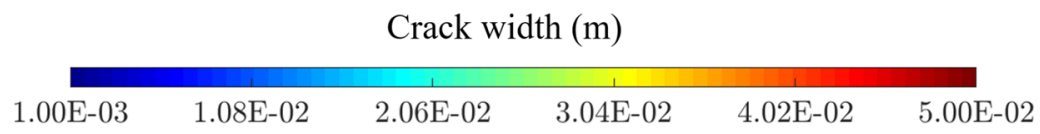

Dead load

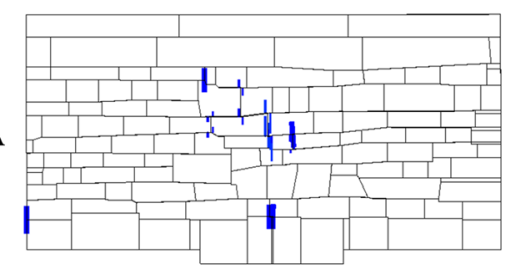

$\mathbf{B}$

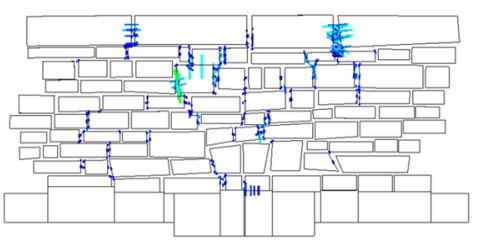

$0.05 \mathrm{~m}$ settlement right
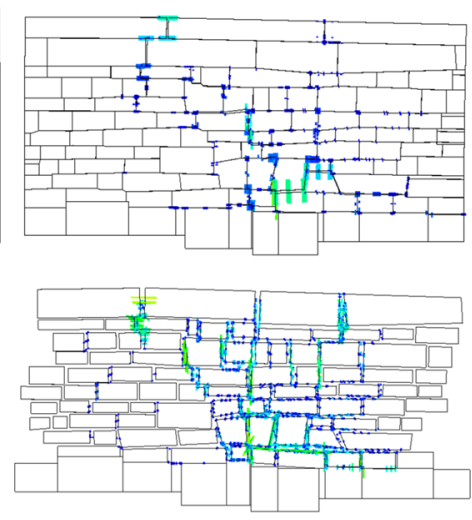

Bricks

Concrete

Fig. 12 Crack widths for the baptistery foundation under three different loading conditions with detailed micro-modeling 
cracks than the simplified version. Additionally, there are regions in the detailed micro-model which exhibit cracking that are not captured by the simplified model. One example of this is the dead load only simulations. With the simplified model as input for the simulations, no cracks form in the upper right-hand joint of the wall. However, with the detailed model as input, cracking is seen to occur. This crack is evident on the existing wall and thus, this indicates that DEM does not predict the full extent of the crack pattern that is predicted with FDEM.

These differences in location, as well as magnitude which can be seen in Fig. 12, are more evident in Fig. 13. Figure 13 is a contour plot comparing the fractional distance of each level of modeling for the three loading cases; the lower values indicate a higher affinity between the simulated cracking and the physical wall. The use of fractional distance (defined in Eq. 1) as a metric for quantitatively comparing crack patterns in simulations and existing conditions has been validated with experimental testing and case studies [47]).

$d_{f}\left(\delta_{e}, \delta_{n}\right)=\frac{\sqrt{\sum_{i=1}^{j_{s}}\left(\delta_{e, i}-\delta_{n, i}\right)^{2}}}{\sqrt{\sum_{i=1}^{j_{s}}\left(\delta_{e, i}\right)^{2}}}$

where $d_{f}$ is the fractional distance, $\delta_{e}$ is the width of the crack on the existing structure, $\delta_{n}$ is the width of the crack in the simulation, and $j_{s}$ is the number of joints considered. Previously, it has been proven that not all of the joints in a structure need to be measured to ascertain fractional distance [47]. The minimum number of joints that need to be accounted for can be calculated using Eq. 2. The joints should be randomly selected so that inconsequential and large openings are both considered; this ensures that both the locations of cracks and the unaffected areas of masonry are weighted.



Fig. 13 Contour plot comparing rack widths for the baptistery foundation under three different loading conditions and two different levels of modeling
$j_{S}=\frac{\frac{z^{2} \times p(1-p)}{e^{2}}}{1+\frac{z^{2} \times p(1-p)}{e^{2} N}}$

where $z$ is the z-score based on a desired confidence level (set to 1.96 based on 95\%), $p$ is the proportion (set to 50\%), $e$ is the desired margin of error (set to $10 \%$ ), and $N$ is the population size.

The contours represent the fractional distance between the existing crack widths and the simulated ones. While the contours are spaced at 0.1 , each step does not necessarily correspond a simulation. Instead the contour lines show the gradient of fractional distances between different simulations. For each case examined, the detailed micro-model has a higher affinity with the existing conditions of the wall than the simplified micro-model. However, it should be noted that if each type of modeling approach is considered individually, the same loading case can be found as the cause of the damage. For instance, looking at the simplified micro-model, the case where there is $0.05 \mathrm{~m}$ of settlement on the left side of the wall has the lowest fractional distance; therefore, this is the loading condition which most probably caused the existing damage on the wall. The case where there is 0.05 $\mathrm{m}$ of settlement on the right is the second most probable, and the case where there is no settlement is the least probable. The order of probability is preserved when considering the affinity of the detailed micro-models. While the detailed micro-models will yield more accurate information about the locations and magnitudes of cracks, for diagnostic purposes, simplified micro-models will also yield the same results. If the resulting simulations were to be used for model updating during stability analysis, the discrepancies between the existing conditions and the simplified micro-model might be exacerbated; this will be examined in a future work.

Both DEM and FDEM have their advantages and limitations as can be seen from the comparison of results in Table 4. The table includes a comparison of the diagnosis, model outputs, as well as computation time. In terms of diagnosis, the results are the same using both approaches. As described previously, both DEM and FDEM selected that $0.05 \mathrm{~m}$ settlement of the left side was closest to the existing conditions of the wall. This indicates that if the primary goal of the research is understanding the origins of damage on a structure, the use of DEM analysis with a simplified micro model is sufficient. Considering how they are different, the outputs of the FDEM model surpass that of the DEM model. While the DEM model can export the displacements of the stones, the widths of cracks that form between adjacent blocks, as well as the location of cracks, it cannot provide information about the stresses that are developing within the mortar since it is not explicitly modeled. Additionally, FDEM captured more of the cracks than DEM. However, 
Table 4 Comparison of DEM and FDEM diagnosis, model outputs, and computation time

\begin{tabular}{lllr}
\hline Method & Diagnosis & Outputs of model & $\begin{array}{c}\text { Computa- } \\
\text { tion time } \\
(\mathrm{s})\end{array}$ \\
\hline DEM & $0.05 \mathrm{~m} \mathrm{~L}$ & Displacements, crack widths, crack locations & 16.38 \\
FDEM & $0.05 \mathrm{~m} \mathrm{~L}$ & $\begin{array}{l}\text { Displacements, crack widths, crack locations, stresses } \\
\text { in mortar, stresses in stones }\end{array}$ & 1785.32 \\
\hline
\end{tabular}

Crack width (m)

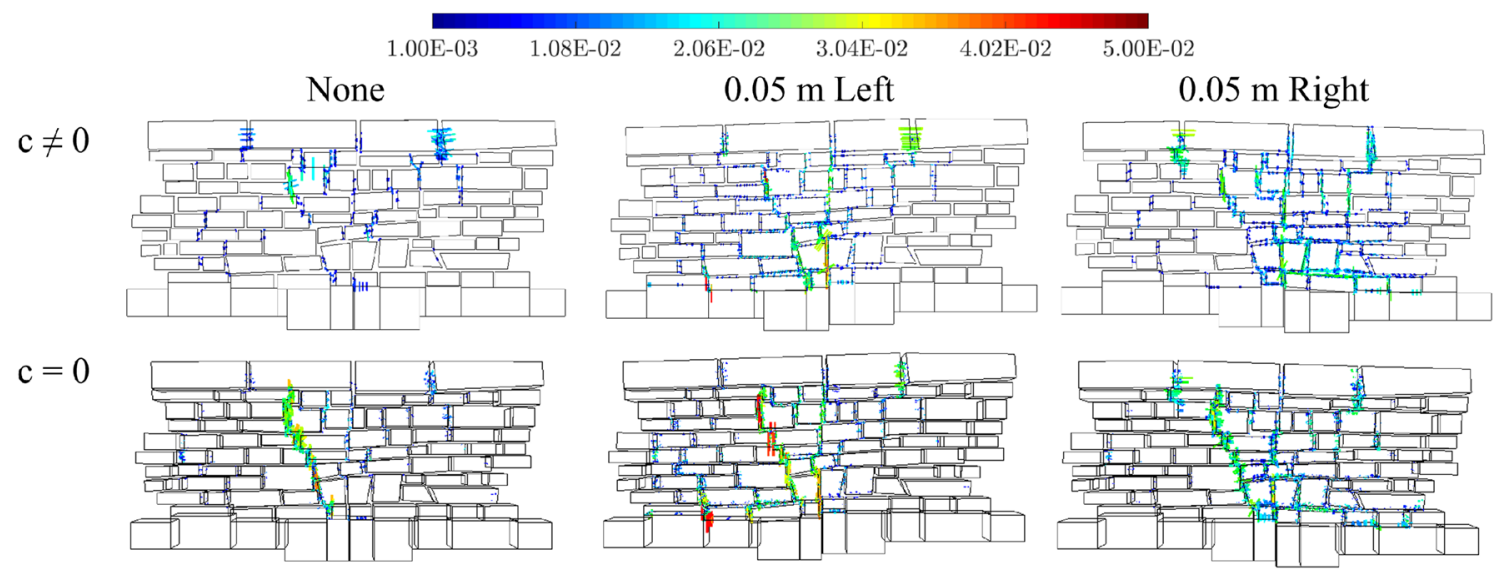

Fig. 14 Comparison of crack widths for different geometries under settlement loading

while the FDEM approach can yield more information, the computation time is much larger; the computation time for FDEM is 109 times longer than the computation time for DEM. The simulations were both executed on a 64-bit operating system with $32.0 \mathrm{~GB}$ of RAM and an Intel Core i7-770K CPU @4.20 GHz. Therefore, depending on the desired deliverables, a project should consider the level of modeling and corresponding numerical method carefully. This decision is directly related to the ground sampling distance (GSD) used in photogrammetry and remote sensing; if detailed micro modeling is appropriate for the scope of the project, a sufficiently small GSD $(<0.005 \mathrm{~m})$ needs to be set to capture millimeter cracking and geometry within the mortar.

\subsection{Alterations in Micro-scale Modeling}

The three geometries shown in Fig. 8 were settled $0.05 \mathrm{~m}$ on the left side to understand how changes in the geometry affect the results of simulation. Figure 14 illustrates the widths of cracks which developed on the wall during the simulations. In the case where the existing geometry is modeled, the cracks are concentrated in the middle of the wall. This closely mimics the existing crack pattern outlined in Fig. 3. Similar to the crack map, in this simulation there is a large crack which occurs in the top, rightmost joint of the wall; only small cracking can be seen outside of these
Table 5 Percent difference from current wall damage for each geometry

\begin{tabular}{ll}
\hline Geometry & $\begin{array}{l}\text { Percent difference } \\
\text { from current wall } \\
\text { damage }\end{array}$ \\
\hline Existing & $14 \%$ \\
Perturbed & $28 \%$ \\
Isodomic & $36 \%$ \\
\hline
\end{tabular}

regions. When the small perturbations are added to the input geometry however, there is a good deal of change in not just the location of the cracking, but also the magnitude. Many smaller regions of cracking (on the order of $1 \mathrm{~mm}$ ) can be seen in the non-central regions of the perturbed simulation. When the input geometry is further perturbed into an isodomic pattern, the crack pattern can again be seen to change. In the isodomic pattern, the magnitude of the cracking has dropped significantly in the middle (from $2 \mathrm{~cm}$ to $1 \mathrm{~mm}$ ) as well as the damage is now spread across a larger surface area. Therefore, considering the cases shown, the results of simulated crack patterns do differ with the changes in the geometry.

These results were also quantitively compared amongst themselves and to the existing crack patterns. Table 5 outlines the percent difference between the simulations of each geometry and the current wall damage. When the geometry 
of the wall is modeled precisely using the laser scan and photogrammetry data, the simulation results are only $14 \%$ different from the existing crack patterns. Since material testing was not carried out for the input parameters, small differences between the two can be accounted for. When small changes were made to the region of interest however, the percent difference from the current wall damage doubled from the case of existing geometry. This indicates that even small changes in the system can affect the diagnosis of damage on a structure and ensuing stability analysis. Lastly, in the case where the geometry of the wall has been idealized in an isodomic pattern, the simulated damage only has a $64 \%$ affinity to the existing conditions where the existing geometry had $86 \%$ affinity. This emphasizes the importance of accurate documentation and modeling when examining damage.

To ensure that this difference was not isolated to this specific load case, additional loading schemes were tested.
Figure 15 is a plot of the crack widths for all three geometries across a spectrum of load cases including:

- dead load

- dead load + settlement of the left side $0.05 \mathrm{~m}$

- dead load + settlement of the right side $0.05 \mathrm{~m}$

- dead load + earthquake with an epicenter to the left of the wall

- dead load + earthquake with an epicenter to the right of the wall

As earthquakes are cyclical in reality, they are often calculated using historical response spectra [63, 64, 70]. While this approach can provide more detailed results, push-over analysis is a widely accepted approximation [3, 35, 42, 56]. For the purposes of this paper, push-over analysis has been utilized which is why the earthquakes are defined as having their epicenters to the left and right of the wall. Across the different geometries, the cracks follow the joints and

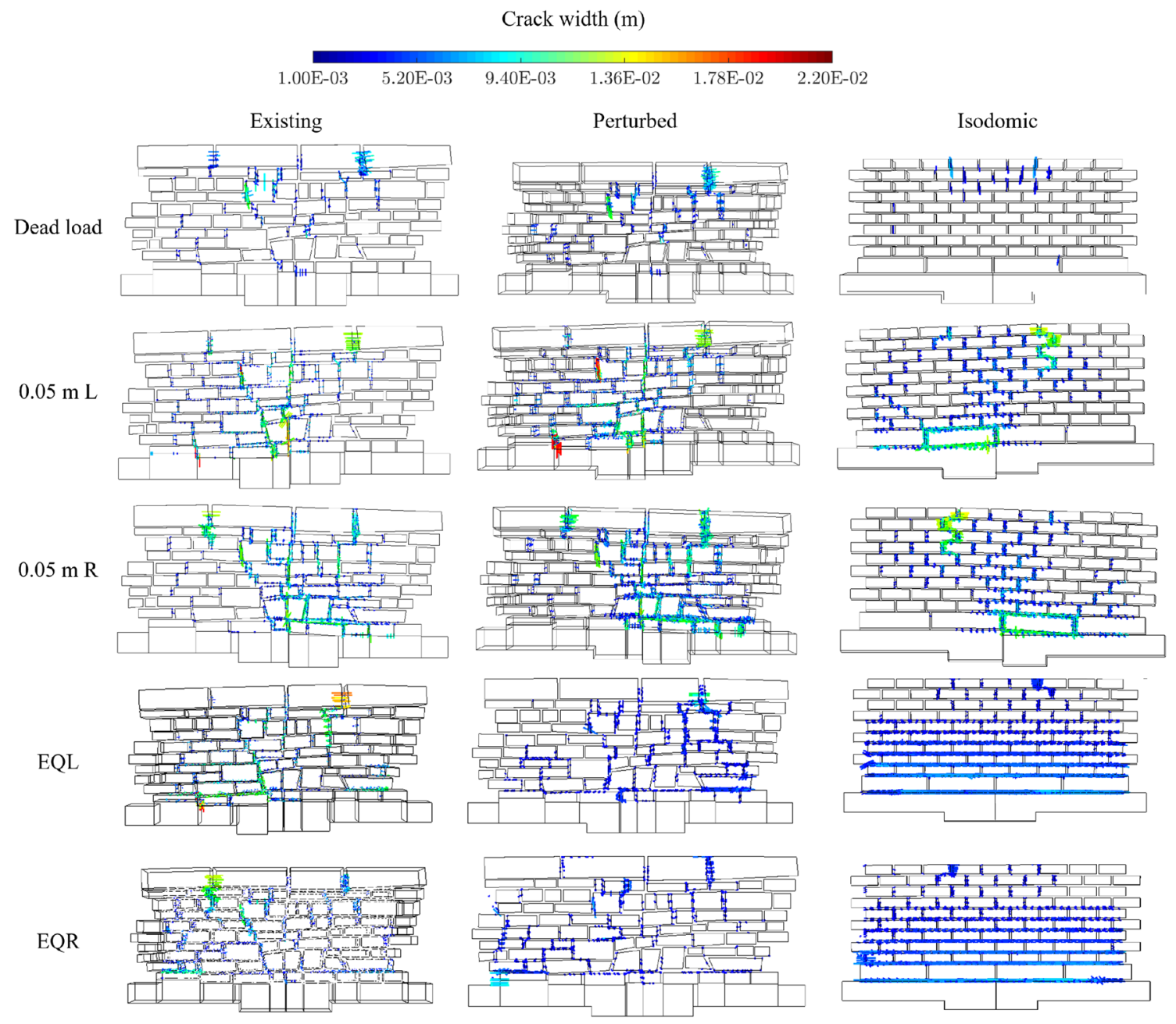

Fig. 15 Comparison of different input geometries across multiple load cases 
therefore the paths themselves differ in each. Considering the case of an earthquake from the left side, the cracks in the existing geometry create continuous paths in the vertical direction since in this geometry it is the path of least resistance. However, in the isodomic pattern, the cracks are mainly horizontal. Therefore, if the simulations were to be used for diagnosing the causes of existing cracks, the isodomic pattern could provide support to a false reason. Additionally, it can be seen that alterations in the geometry affect the ensuing crack pattern not only in location but also in magnitude. As the figure is traversed from existing to isodomic, the maximum crack width of the wall drops noticeably. Again, in the case of an earthquake from the left side, the crack width drops from $2 \mathrm{~cm}$ to $4 \mathrm{~mm}$. These simulations suggest that the geometry of the input model plays a critical role in understanding damage on an existing structure.

Similarly, three geometries of the Room of the Elements shown in Fig. 9 were compared for the case that most probably caused the existing damage- $0.1 \mathrm{~m}$ settlement of the middle section of the wall [49]. Figure 16 shows the widths of cracks which formed on the wall over the course of the simulations. Considering the cases shown in Fig. 16, again the crack patterns differ with the changes in the geometry. While, the cracks along the door frames are similar in the existing case and the idealized case, the magnitude of the cracking decreases in the semi-idealized geometry. Additionally, in the semi-idealized geometry, there is less cracking occurring in the middle of the wall. In the case of the existing geometry as well as the idealized one, there is cracking scattered across the middle section of the wall on the order of $1-9 \mathrm{~mm}$; in the semi-idealized case, there is not any cracking in this region. Similar to the case of the baptistery, these differences were consistent across all loading conditions analyzed. Thus, when analyzing damage on a building, reality-based imaging methods should be used at least at preliminary levels for building pathology and diagnostics.

\subsection{Effects of Initial Conditions}

In addition to examining the consequences of input geometry, this work examines the effects of unknown initial conditions for two case studies: (1) a possible preexisting joint in the baptistery foundation and (2) unknown filler material in the Room of the Elements.

Figure 17 is a plot of crack widths for the two cases of the baptistery foundation wall (with a crack in the joint of interest, $c=0$, and without $c \neq 0$ ) across three different loading conditions. As can be seen qualitatively, the crack patterns incurred by the structure vary for each case. Not only does the crack width vary in the region of interest, additionally, there are larger cracks occurring in other sections of the structure.

Figure 18 is a contour plot of the fractional distance between the existing conditions and the simulations considering different cohesion in the region of interest and different loading schemes. In each instance where the simulation has cohesion in the region of interest, there is a higher level of affinity with the existing conditions of the wall. In the cases where there is cohesion, the left settlement cracking is the most affine, the right side is the second most, and the case where there is no settlement is the least affine. However, in the cases where there is no cohesion, the delineation is less clear. The settlement of the left side again is the most affine but the difference between this case and the second most affine is much less than the difference for the simulations with cohesion. When there is cohesion, the difference between the most probable and the second most probable case is 0.41 ; where there is no cohesion, the difference is 0.96 . This difference between the different loading schemes indicates that the influence of the preexisting joint dominates over the influence of the different loading schemes.

For the Room of the Elements, the results qualitatively illustrate the same concept as the foundation wall of the Baptistery: variations in initial conditions, such as material choice, affect the results of the ensuing simulations. Figure 19 is a plot of (1) the wall simulated with brick and (2) the wall simulated with concrete infill in the unknown

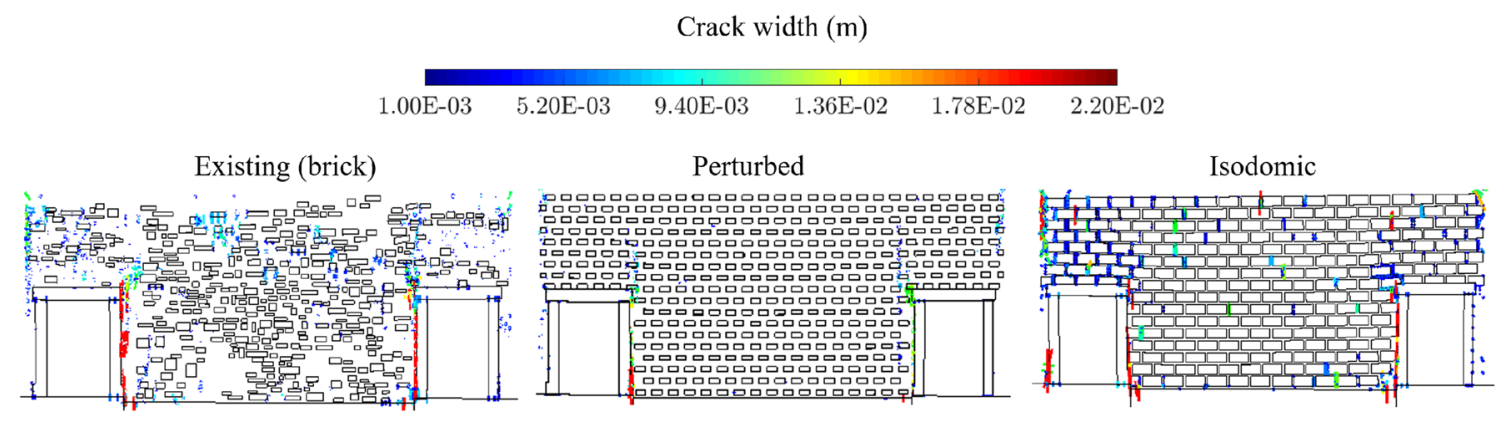

Fig. 16 Comparison of crack widths for different geometries under settlement loading 


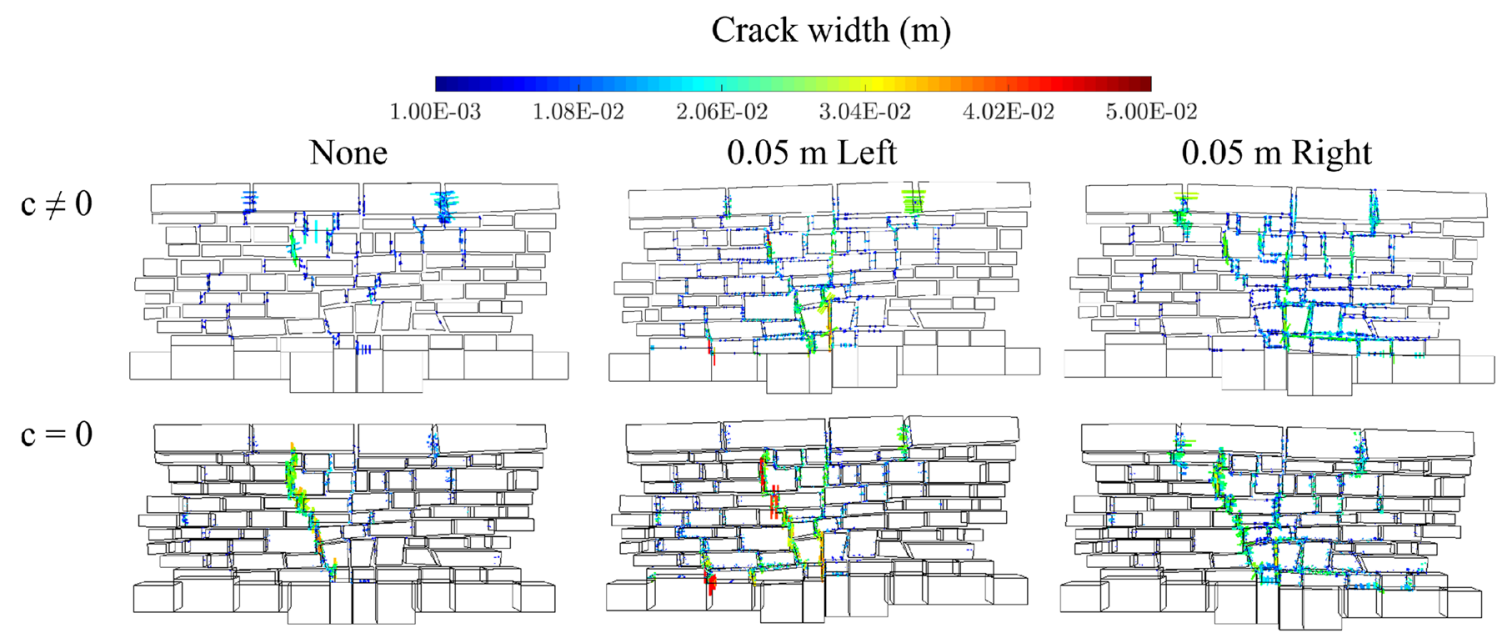

Fig. 17 Detailed micro-modeling of the baptistery foundation for three different loading conditions and with two different initial assumptions (uncracked and cracked)

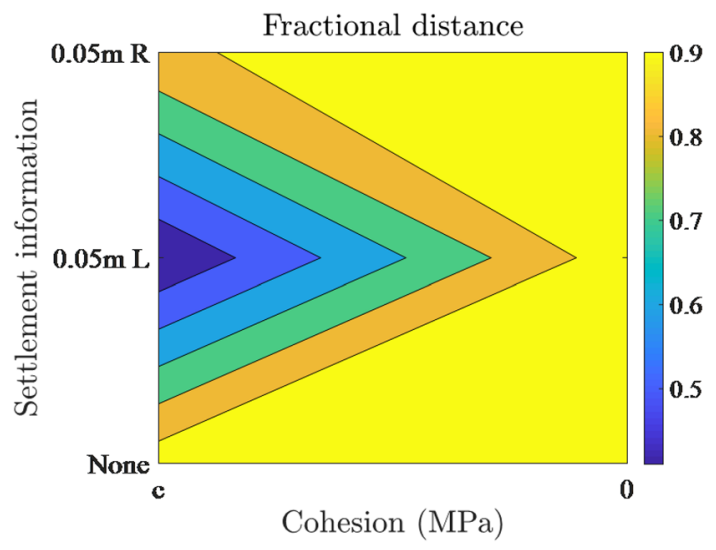

Fig. 18 Contour plot illustrating the fractional distance between the simulations and the existing foundation wall for two initial assumptions ( $c=0$ and $c \neq 0)$ across three loading scenarios

regions. Each geometry is simulated under two different loading scenarios: dead load and deada load $+0.1 \mathrm{~m}$ settlement of the middle of the wall. Considering just the dead load, it can be seen that in the simulation where there is concrete infill instead of the bricks there is more cracking present.

The propagation of a crack in the wall with concrete infill takes less energy than a crack in the wall with bricks. This is because Young's modulus of brick is much higher than that of concrete infill. A crack in the wall with the brick would either need to be energetic enough to pass through the brick or have enough energy to increase its path length and go around. In the wall with the concrete infill, the crack would just need enough energy to pass through the infill; this is less than the energy it would need to pass through the brick. The results are similar for the settlement loading; there are more cracks with larger widths occurring on the wall with the concrete infill than on the wall with the brick. Therefore, these results support the results of the Baptistery di San Giovanni in stressing the importance of initial conditions. This highlights the need for integrating additional techniques at multiple surface levels such as thermal imaging, geophysical radar, etc. when diagnosing damages on a structure.

\section{Conclusions}

This study shows the results from comparing different levels of documentation and numerical modeling used in building pathology and diagnostics. For this work, the geometry and existing damage were captured for a foundation wall in the Baptistery di San Giovanni in Florence, Italy and for a wall in the Room of Elements in Palazzo Vecchio. They were documented using a combination of photogrammetry, laser scanning, and thermal imaging. To understand the differences in diagnostics and analysis using simplified micro-modeling versus detailed micromodeling, a 3D model of the baptistery wall was made 1) without the joints explicitly modeled and 2) with the joints explicitly modeled. This wall was then subjected to a variety of loading conditions to understand the effects of the disparate levels of modeling. Using the fractional distance between the simulation results and the existing wall to understand the effects, it was seen that consistently the wall with the mortar explicitly modeled had a higher affinity to the existing conditions. While the detailed micro-model did provide higher accuracy, the results in diagnostics were the same. Both types of modeling were able to identify that $0.05 \mathrm{~m}$ of settlement on the left side of the structure was the most probable cause of the existing 


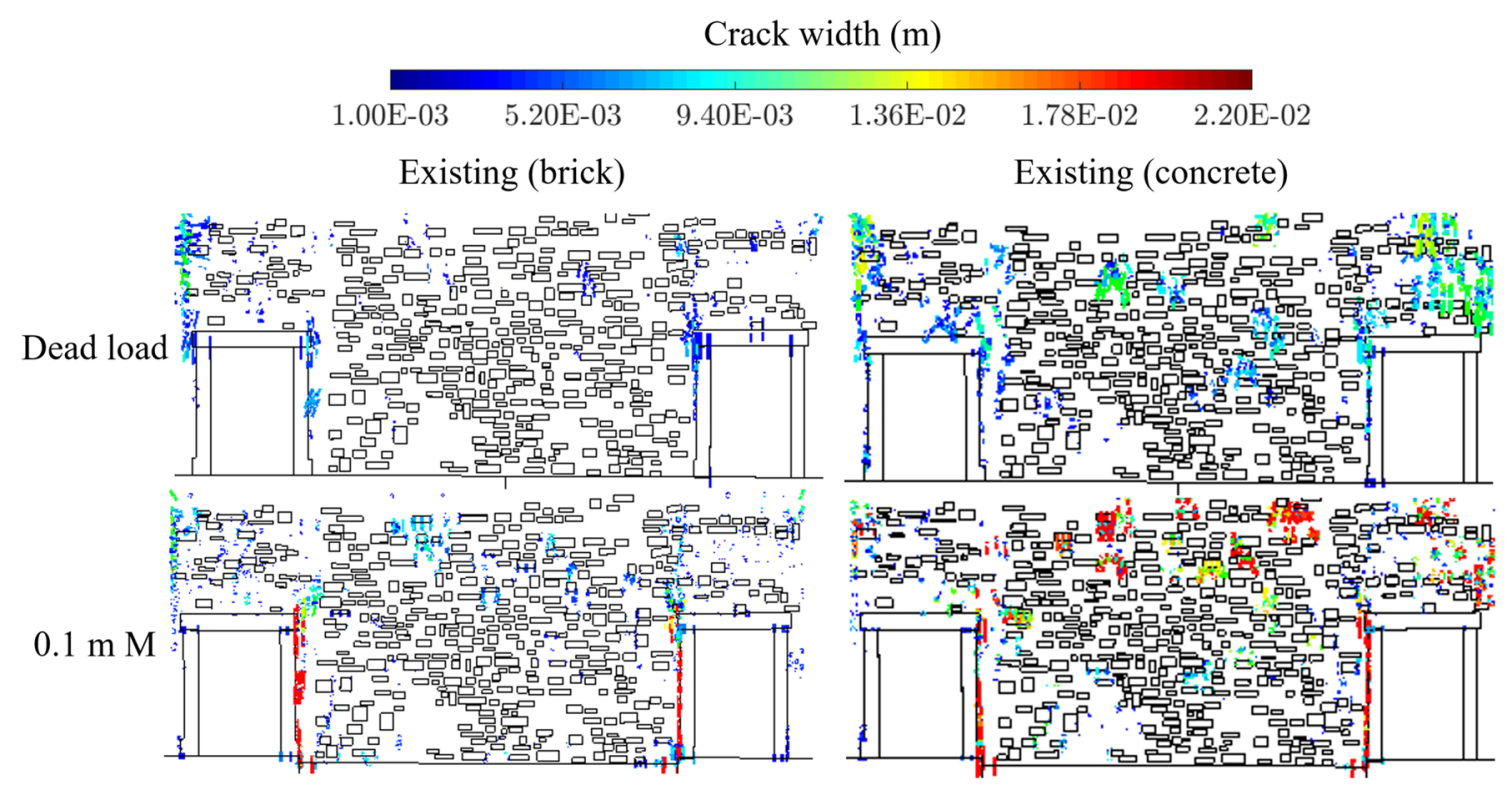

Fig. 19 Detailed micro-modeling of the wall in the Room of the Elements for different loading conditions and with two different initial assumptions (brick and infill)

damage. Therefore, these results indicate that for building pathology and diagnostics purposes, the detailed and simplified micro-model perform similarly. Thus, if this is the only aim of a project, simplified micro-modeling should be used since it has a significantly lower computation time. In the case that information about stresses building in the mortar is of paramount interest to a project, detailed micro-modeling and a sufficiently small GSD should be used to capture millimeter cracking and geometry within the mortar.

The second aim of this paper was to understand how changes in macro-scale modeling can affect the results of simulation. To study this, three different 3D models of both the Baptistery di San Giovanni's foundation wall and the wall in the Room of the Elements were generated. For the foundation wall, the first model was derived from the laser scan data and captured the geometry of the stones and the mortar exactly; the second model altered the position of stones by increasing the path length in a specific joint; the third model was an idealized one which fully elongated all joint lengths. For the wall in the Room of the Elements, the first model was of the existing pattern of stones, the second was a semi-idealized form, and the third was a fully idealized form. All of these models were simulated using FDEM under a variety of loading conditions. For both case studies, the cause of the existing cracking was known from previous studies. Using this information, the results of the simulations were compared to each other. It was found that the geometry which matched the existing conditions had the highest affinity with the existing crack patterns; a similar result was found for the Room of the Elements. Since these results indicate that the geometry of the input model does play a crucial role in understanding damage, reality-based imaging methods should be used at least at preliminary levels for building pathology.

The final aim of this paper was to understand how initial assumptions about the existence of damage or material properties could alter the results of simulation. The foundation wall was modeled with and without a preexisting joint; the wall in the Room of the Elements was modeled with brick infill and with concrete infill. Considering the simulations of the foundation wall, it was seen that the crack width varies between the two input parameters not only within the region of interest but also in neighboring regions. The case where $c=0$ was seen to impact the simulations across the board; the fractional distance for the walls with $c=0$ and $c \neq 0$ were compared and it was found that in every case, even those where the settlement did not cause the cracking patterns, the wall with $c=0$ had lower affinity with existing conditions. In addition to this study, an assessment of the walls in the Room of the Elements was carried out which supported the results of the foundation wall. These results illustrated the importance of multi-level documentation which integrates surface imaging with sub-surface investigative methods.

As shown in this paper, for an in-depth understanding of the condition of a structure, at least preliminary documentation and simplified micro-modeling are appropriate. However, there are many cases where the entirety of the structure cannot be seen by the naked eye. The last part of this paper emphasizes the importance of integrating additional levels of documentation such as GPR and thermal imaging into the 
process to ensure the accuracy of a resulting model. By integrating reality-based imaging and sub-surface investigation methods, existing damage on a structure can be accurately assessed for preservation and monitoring. While this study only examined diagnosis of cracks in masonry structures, future work will be done to see how levels of documentation and modeling can impact stability analysis.

Acknowledgements This work was supported by the Department of Civil and Environmental Engineering, the Council on Science and Technology, the Dean's Fund for Innovation, and the School of Engineering and Applied Sciences at Princeton. Additional support was provided by the Kinsella Fund, the Qualcomm Institute at UC San Diego, the Friends of CISA3, and the World Cultural Heritage Society. This material is based upon work supported by the National Science Foundation Graduate Research Fellowship Program under Grants No. DGE-1656466 and No. DGE-0966375, 'Training, Research and Education in Engineering for Cultural Heritage Diagnostics,' and award No. CNS-1338192, 'MRI: Development of Advanced Visualization Instrumentation for the Collaborative Exploration of Big Data.'. Any opinions, findings and conclusions or recommendations expressed in this material are those of the authors and do not necessarily reflect the views of the National Science Foundation. Opinions, findings, and conclusions from this study are those of the authors and do not necessarily reflect the opinions of the research sponsors. This work was completed as part of the Itasca Educational Partnership under the mentorship of Dr. Jim Hazzard.

\section{Compliance with Ethical Standards}

Conflicts of interest The authors declare no conflict of interest.

Open Access This article is distributed under the terms of the Creative Commons Attribution 4.0 International License (http://creativeco mmons.org/licenses/by/4.0/), which permits unrestricted use, distribution, and reproduction in any medium, provided you give appropriate credit to the original author(s) and the source, provide a link to the Creative Commons license, and indicate if changes were made.

\section{References}

1. Addison AC (2000) Emerging trends in virtual heritage. IEEE Multimed 7(2):22-25

2. Alessandri C, Cappelli E, Leggeri B, Muccini U, Tralli A (1970) Critical discussion about some measurements on a damaged corner of Palazzo Vecchio. WIT Trans Built Environ 16

3. Araújo AS, Lourenço PB, Oliveira DV, Leite JC (2012) Seismic assessment of St. James church by means of pushover analysis: before and after the New Zealand earthquake. Open Civ Eng J 6(SPEC. ISS. 1):160-172

4. Asteris PG, Sarhosis V, Mohebkhah A, Plevris V, Papaloizou L, Komodromos P, Lemos JV (2015) Numerical modeling of historic masonry structures. In: Handbook of research on seismic assessment and rehabilitation of historic structures. IGI Global, pp 213-256

5. Autodesk: Cut, rough granite (2016). Online https://www.autod esk.com/

6. Baraldi D, Reccia E, Cazzani A, Cecchi A (2013) Comparative analysis of numerical discrete and finite element models: the case of in-plane loaded periodic brickwork. Compos Mech 4:319-344
7. Baraldi D, Reccia E, Cecchi A (2018) In plane loaded masonry walls: DEM and FEM/DEM models a critical review. Meccanica 53(7):1613-1628

8. Block P, Ciblac T, Ochsendorf J (2006) Real-time limit analysis of vaulted masonry buildings. Comput Struct 84(29-30):1841-1852

9. Brutto ML, Meli P (2012) Computer vision tools for 3D modelling in archaeology. Int J Herit Digit Era 1((1-suppl)):1-6

10. Bui T, Limam A, Sarhosis V, Hjiaj M (2017) Discrete element modelling of the in-plane and out-of-plane behaviour of dry-joint masonry wall constructions. Eng Struct 136:277-294

11. Caliò I, Cannizzaro F, Marletta M (2010) A discrete element for modeling masonry vaults. In: Advanced materials research, vol 133. Trans Tech Publ, pp 447-452

12. Carpinteri A, Invernizzi S, Lacidogna G (2005) In situ damage assessment and nonlinear modelling of a historical masonry tower. Eng Struct 27(3):387-395

13. Clemente R (2006) Structural analysis of historical buildings by localized cracking models. PhD dissertation, Universitat Politècnica de Catalunya, Barcelona, Spain

14. Costanzo A, Minasi M, Casula G, Musacchio M, Buongiorno MF (2014) Combined use of terrestrial laser scanning and IR thermography applied to a historical building. Sensors 15(1):194-213

15. Cundall P, Hart R (2015) Theory and background:3dec 3 dimensional distinct element code. Tech. rep, Itasca Consulting Group

16. de Martino G, Giamundo V, Lignola G (2012) Seismic vulnerability of the marble blocks colonnade of ancient forum in the Archaeological Site of Pompeii. In: 15th World conference on earthquake engineering (paper 4323, pp 1-10), Lisbon, Portugal

17. DeJong MJ, Vibert C (2012) Seismic response of stone masonry spires: computational and experimental modeling. Eng Struct 40:566-574

18. Douglas I, Napolitano R, Garlock M, Glisic B (2019) Reconsidering the vaulted forms of Cuba's National School of Ballet. In: Structural analysis of historical constructions. Springer, New York, pp 2150-2158

19. Drdáckỳ M, Fratini F, Frankeová D, Slížková Z (2013) The Roman mortars used in the construction of the Ponte di Augusto (Narni, Italy)-a comprehensive assessment. Constr Build Mater 38:1117-1128

20. El-Hakim S, Beraldin J, Remondino F, Picard M, Cournoyer L, Baltsavias E (2008) Using terrestrial laser scanning and digital images for the 3D modelling of the Erechteion, Acropolis of Athens. In: Proceedings of DMACH conference, pp 3-16

21. Fais S, Cuccuru F, Ligas P, Casula G, Bianchi MG (2017) Integrated ultrasonic, laser scanning and petrographical characterisation of carbonate building materials on an architectural structure of a historic building. Bull Eng Geol Environ 76(1):71-84

22. Fang DL, Napolitano RK, Michiels TL, Adriaenssens SM (2018) Assessing the stability of unreinforced masonry arches and vaults: a comparison of analytical and numerical strategies. Int J Archit Herit $1-15$

23. Fangi $G$ (2011) The multi-image spherical panoramas as a tool for architectural survey. CIPA Heritage Documentation 21

24. Federman A, Shrestha S, Quintero M, Mezzino D, Gregg J, Kretz S, Ouimet C (2018) Unmanned aerial vehicles (uav) photogrammetry in the conservation of historic places: Carleton immersive media studio case studies. Drones 2(2):18

25. González-Aguilera D, Gómez-Lahoz J, Muñoz-Nieto Á, Herrero-Pascual J (2008) Monitoring the health of an emblematic monument from terrestrial laser scanner. Nondestruct Test Eval 23(4):301-315

26. González-Aguilera D, Gómez-Lahoz J, Sánchez J (2008) A new approach for structural monitoring of large dams with a threedimensional laser scanner. Sensors 8(9):5866-5883

27. Gotti E, Oleson J, Bottalico L, Brandon C, Cucitore R, Hohlfelder $\mathrm{R}$ (2008) A comparison of the chemical and engineering 
characteristics of ancient roman hydraulic concrete with a modern reproduction of vitruvian hydraulic concrete. Archaeometry 50(4):576-590

28. Harris SY (2001) Building pathology: deterioration, diagnostics, and intervention. Wiley, Hoboken

29. Hess M (2018) Diagnostic structural health assessment through layered integration of non-destructive imaging data. $\mathrm{Ph} . \mathrm{D}$. thesis, University of California San Diego

30. Hess M, Vanoni D, Petrovic V, Kuester F (2015) High-resolution thermal imaging methodology for non-destructive evaluation of historic structures. Infrared Phys Technol 73:219-225

31. Inc., I.S. (2014) Emissivity values for common materials. http:// www.infrared-thermography.com/material-1.htm

32. Kavanaugh C, Morris IM, Napolitano R, Jorquera-Lucerga JJ (2017) Validating the use of graphical thrust line analysis for pier buttresses: the case study of Amiens Cathedral. Int J Archit Herit 11(6):859-870

33. Kersten T P, Lindstaedt M (2012) Automatic 3D object reconstruction from multiple images for architectural, cultural heritage and archaeological applications using open-source software and web services. Photogrammetrie-Fernerkundung-Geoinf 6:727-740

34. Kilic G (2015) Using advanced ndt for historic buildings: towards an integrated multidisciplinary health assessment strategy. J Cult Herit 16(4):526-535

35. Kim S, D'Amore E (1999) Push-over analysis procedure in earthquake engineering. Earthq Spectra 15(3):417-434

36. Lagüela S, Solla M, Puente I, Prego FJ (2018) Joint use of gpr, irt and tls techniques for the integral damage detection in paving. Constr Build Mater 174:749-760

37. Lemos JV (2007) Discrete element modeling of masonry structures. Int J Archit Herit 1(2):190-213

38. Lerma JL, Navarro S, Cabrelles M, Villaverde V (2010) Terrestrial laser scanning and close range photogrammetry for $3 \mathrm{D}$ archaeological documentation: the upper palaeolithic cave of parpalló as a case study. J Archaeol Sci 37(3):499-507

39. Letellier R, Eppich R (2015) Recording, documentation and information management for the conservation of heritage places. Routledge, Abingdon

40. Lourenço PB (2002) Computations on historic masonry structures. Prog Struct Mat Eng 4(3):301-319

41. Lubowiecka I, Armesto J, Arias P, Lorenzo H (2009) Historic bridge modelling using laser scanning, ground penetrating radar and finite element methods in the context of structural dynamics. Eng Struct 31(11):2667-2676

42. Mele E, De Luca A, Giordano A (2003) Modelling and analysis of a basilica under earthquake loading. J Cult Herit 4(4):355-367

43. Meola C, Di Maio R, Roberti N, Carlomagno GM (2005) Application of infrared thermography and geophysical methods for defect detection in architectural structures. Eng Fail Anal 12(6):875-892

44. Michiels T, Napolitano R, Adriaenssens S, Glisic B (2017) Comparison of thrust line analysis, limit state analysis and distinct element modeling to predict the collapse load and collapse mechanism of a rammed earth arch. Eng Struct 148:145-156

45. Milani G, Valente M, Alessandri C (2018) The narthex of the church of the nativity in Bethlehem: a non-linear finite element approach to predict the structural damage. Comput Struct 207:3-18

46. Napolitano R, Douglas I, Garlock M, Glisic B (2017) Virtual tour environment of Cuba's National School of Art. ISPRS-International Archives of the Photogrammetry, Remote Sensing and Spatial Information Sciences, pp 547-551

47. Napolitano R, Glisic B (2019) Methodology for diagnosing crack patterns in masonry structures using photogrammetry and distinct element modeling. Eng Struct 181:519-528
48. Napolitano R, Hess M, Coe-Scharff R, Glisic B (2019) Numerical modeling of crack propagation in masonry structures. In: Structural analysis of historical constructions. Springer, New York, pp 826-834

49. Napolitano R, Hess M, Glisic B (2019) Integrating non-destructive testing, laser scanning, and numerical modeling for damage assessment: the room of the elements. Heritage 2(1):151-168

50. Napolitano R, Hess M, Glisic B (2019) The foundation walls of the Baptistery di San Giovanni: a combination of laser scanning and finite-distinct element modeling to ascertain damage origins. Int J Archit Herit (in revisions)

51. Napolitano R, Lansing L, Glisic B (2019) Understanding the function of roman bonding courses: a numerical approach. In: Structural analysis of historical constructions. Springer, New York, pp 1798-1806

52. Napolitano RK, Scherer G, Glisic B (2018) Virtual tours and informational modeling for conservation of cultural heritage sites. J Cult Herit 29:123-129

53. Park H, Lee H, Adeli H, Lee I (2007) A new approach for health monitoring of structures: terrestrial laser scanning. Comput-Aid Civ Infrastruct Eng 22(1):19-30

54. Patias P, Santana M (2011) Introduction to heritage documentation. CIPA Herit Doc Best Pract Appl 38:5

55. Peña F, Lourenço PB, Mendes N, Oliveira DV (2010) Numerical models for the seismic assessment of an old masonry tower. Eng Struct 32(5):1466-1478

56. Penelis GG (2006) An efficient approach for pushover analysis of unreinforced masonry (URM) structures. J Earthq Eng 10(03):359-379

57. Psycharis IN, Lemos J, Papastamatiou D, Zambas C, Papantonopoulos C (2003) Numerical study of the seismic behaviour of a part of the parthenon pronaos. Earthq Eng Struct Dyn 32(13):2063-2084

58. Pulatsu B, Bretas EM, Lourenco PB (2016) Discrete element modeling of masonry structures: validation and application. Earthq Struct 11(4):563-582

59. Ramos LF, Lourenço PB (2004) Modeling and vulnerability of historical city centers in seismic areas: a case study in Lisbon. Eng Struct 26(9):1295-1310

60. Reccia E, Cazzani A, Cecchi A (2012) FEM-DEM modeling for out-of-plane loaded masonry panels: a limit analysis approach. Open Civ Eng J 6((Suppl 1-M10)):231-238

61. Roca P (2004) Considerations on the significance of history for the structural analysis of ancient constructions. Structural analysis of historical constructions IV. Balkema, Amsterdam pp, pp 63-73

62. Rosina E, Scaioni M, L'Erario A, Diaz-Vilarino L et al (2017) Integration of infrared thermography and photogrammetric surveying of built landscape

63. Russo S (2013) On the monitoring of historic Anime Sante church damaged by earthquake in L'aquila. Struct Control Health Monit 20(9):1226-1239

64. Russo V, Lignola GP, Vassallo E, Zinno A (2010) Second world war damages of the architectural heritage: St. Maria del Popolo Agli Incurabili church in Naples. In: Advanced materials research, vol 133. Trans Tech Publ, pp 1137-1142

65. Saleri R, Cappellini V, Nony N, De Luca L, Pierrot-Deseilligny M, Bardiere E, Campi M (2013) UAV photogrammetry for archaeological survey: the theaters area of Pompeii. In: 2013 Digital heritage international congress (DigitalHeritage), vol 2. IEEE, pp 497-502

66. Sarhosis V, Bagi K, Lemos J, Milani G (2016) Computational modeling of masonry structures using the discrete element method. Advances in Civil and Industrial Engineering, IGI Global

67. Sarhosis V, Garrity S, Sheng Y (2015) Influence of brick-mortar interface on the mechanical behaviour of low bond strength masonry brickwork lintels. Eng Struct 88:1-11 
68. Sarhosis V, Lignola GP, Asteris PG (2015) Seismic vulnerability of ancient colonnade: two story colonnade of the forum in Pompeii. In: Handbook of research on seismic assessment and rehabilitation of historic structures. IGI Global, pp 331-358

69. Sarhosis V, Sheng Y (2014) Identification of material parameters for low bond strength masonry. Eng Struct 60:100-110

70. Sevim B, Bayraktar A, Altunişik AC, Atamtürktür S, Birinci F (2011) Finite element model calibration effects on the earthquake response of masonry arch bridges. Finite Elem Anal Des 47(7):621-634

71. Shrestha S, Reina Ortiz M, Gutland M, Napolitano R, Morris I, Santana Quintero M, Erochko J, Kawan S, Shrestha R, Awal $P$ et al (2017) Digital recording and non-destructive techniques for the understanding of structural performance for rehabilitating historic structures at the Kathmandu valley after Gorkha earthquake 2015. ISPRS Annals of Photogrammetry, Remote Sensing \& Spatial Information Sciences 4

72. Smoljanović H, Živaljić N, Željana N (2013) A combined finitediscrete element analysis of dry stone masonry structures. Eng Struct 52:89-100. https://doi.org/10.1016/j.engstruct.2013.02.010

73. Stylianidis E, Patias P, Liapakis C, Balis V, Philotheou G (2005) Visualization of frescos by means of photogrammetry and laser scanning. In: Proceedings of 20th international CIPA symposium on international cooperation to save the World's Cultural Heritage, vol 26

74. Taylor J (2005) An integrated approach to risk assessments and condition surveys. J Am Inst Conserv 44(2):127-141
75. Vasconcelos G, Lourenço P, Alves C, Pamplona J (2008) Ultrasonic evaluation of the physical and mechanical properties of granites. Ultrasonics 48(5):453-466

76. Verdiani G, Braghiroli A (2012) The ancient fragment collection at the Museo Archeologico in Florence, Italy, a digital proposal to allow its access. In: Euro-Mediterranean conference. Springer, New York, pp 461-468

77. Walker R (2016) Density of materials. https://www.simetric.co.uk/ si_materials.htm

78. Wang CP, Huang Y, Hsu SC, Hong J J (2018) Identifying the defects presented on the exterior layers of a structure by employing $3 \mathrm{~d}$ point clouds and thermography. In: Civil Infrastructures Confronting Severe Weathers and Climate Changes Conference, pp. 101-108. Springer

79. Watt DS (2009) Building pathology: principles and practice. Wiley, Hoboken

80. Zara J, Slavík P (2003) Cultural heritage presentation in virtual environment: Czech experience. In: 14th International workshop on database and expert systems applications, 2003. Proceedings. IEEE, pp 92-96

Publisher's Note Springer Nature remains neutral with regard to jurisdictional claims in published maps and institutional affiliations. 